\title{
EFEITO DA ADIÇÃO DE SERRAGEM DE COURO TRATADA QUIMICAMENTE NAS PROPRIEDADES DO CIMENTO PORTLAND
}

Daniel Véras Ribeiro*, Shih Yung Yuan e Márcio Raymundo Morelli

Departamento de Engenharia de Materiais, Universidade Federal de São Carlos, Rodovia Washington Luis, km 235, 13565-905

São Carlos - SP, Brasil

Recebido em 24/8/10; aceito em 21/12/10; publicado na web em 14/3/11

\begin{abstract}
EFFECT OF CHEMICALLY TREATED SHAVE LEATHER ADDITION ON THE CHARACTERISTICS OF PORTLAND CEMENT PASTES. The sheave leather was subjected to chemical treatment in an attempt to immobilize chromium ion in a matrix of cement. Cementitious pastes were obtained by adding different proportions of waste treated solutions ( 5 and $10 \%$ compared to the cement mass) and the $\mathrm{pH}$ and setting time (hardening) were measured. Aiming to check the leather influence in Portland cement pastes, the phases formation were observed by X-ray diffraction (XRD). The results showed that the pretreatment was effective for the waste dissolution and the $\mathrm{pH}$ of treated waste chemical solutions did not influence significantly the characteristics of cement paste, with a slight increase in setting time results.
\end{abstract}

Keywords: shave leather; Portland cement; inertization.

\section{INTRODUÇÃO}

O Brasil, segundo maior produtor e quarto maior exportador de couros do mundo (de acordo com o Centro das Indústrias de Curtume do Brasil, $\left.{ }^{1} \mathrm{CICB}\right)$, tem aumentado sua preocupação no tocante aos problemas associados à geração de resíduos perigosos, tais como a serragem de couro e o grande volume de efluentes líquidos resultantes do processamento das peles, principalmente entre as etapas de ribeira e curtimento (wet blue). Segundo Pacheco, ${ }^{2}$ o consumo total médio de água nos curtumes brasileiros é de aproximadamente $32 \mathrm{~m}^{3}$ para cada tonelada de pele salgada.

Apesar de o cromo ser adicionado ao processo de curtimento em sua forma trivalente (menos tóxica do que a forma hexavalente, que é cancerígena), o resíduo proveniente deste processo é classificado, segundo a norma NBR 10004/2004, como classe I (perigoso) necessitando, assim, de um tratamento adequado antes da deposição em aterros controlados.

O sulfato de cromo é o reagente mais utilizado no processo de curtimento mineral e sua concentração no banho de curtimento é de cerca de 1,5-5,0\%, em relação ao peso total bruto inicial de pele salgada. O sulfato básico de cromo é obtido conforme a Equação 1:

$$
\mathrm{Na}_{2} \mathrm{Cr}_{2} \mathrm{O}_{7}+\mathrm{H}_{2} \mathrm{O}+3 \mathrm{SO}_{2} \rightarrow 2 \mathrm{Cr}(\mathrm{OH}) \mathrm{SO}_{4}+\mathrm{Na}_{2} \mathrm{SO}_{4}
$$

O cromo, adicionado em forma de sulfato, atua como ponte, interligando os grupos proteicos do couro (Figura 1), resultando em uma maior estabilidade química e mecânica do produto final. ${ }^{3}$

A serragem cromada (conhecida também como raspa de couro) é oriunda da máquina de rebaixar, que uniformiza a espessura do couro e, devido ao seu baixo peso específico, apresenta um grande volume. A serragem cromada apresenta uma umidade de $40 \%$ e, em base seca, o teor de cromo pode chegar a $3 \%$. Normalmente são gerados cerca de $100 \mathrm{~kg}$ deste tipo de resíduo para cada tonelada de couro salgado. ${ }^{4}$ Esta elevada geração da raspa de couro é motivo de forte

*e-mail: verasribeiro@hotmail.com

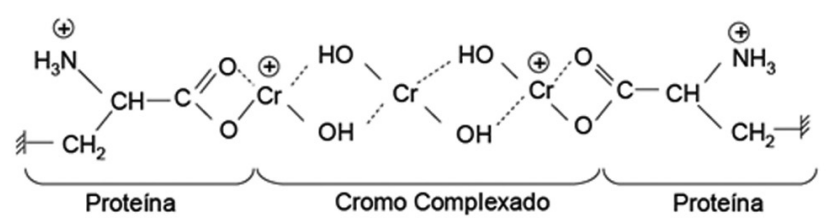

Figura 1. Rede estrutural do couro após o processo de curtimento (couro wet blue)

preocupação ambiental e, com o intuito de buscar uma alternativa ambientalmente adequada para a sua inertização, propõe-se o uso como aditivo em matriz cimentícia.

Matrizes alcalinas como as de cimento Portland são comumente usadas no acondicionamento de resíduos por serem relativamente baratas, serem bastante conhecidas e de tecnologia facilmente acessível. Além disso, sua elevada alcalinidade reduz a solubilidade de muitos resíduos inorgânicos tóxicos e perigosos, inibe os processos microbiológicos e, por necessitarem de água para a hidratação, podem incorporar resíduos líquidos, pastosos e úmidos, ${ }^{5}$ como a raspa de couro.

Apesar de tradicionalmente serem utilizados parâmetros físicos, tais como resistência mecânica e porosidade para avaliar a qualidade de matrizes cimentícias, conceitos químicos normalmente aplicados às soluções aquosas, como $\mathrm{pH}$ e potencial de oxirredução, são parâmetros de caracterização fundamentais para entender algumas destas propriedades físicas, devido à presença de água nos poros da matriz.

Nos processos de estabilização e/ou solidificação, os metais apresentam-se formando hidróxidos e sua solubilidade é determinada pelo $\mathrm{pH}$. Desta maneira, a habilidade do sistema em imobilizar metais é dependente do seu $\mathrm{pH}$ e quanto mais insolúvel for o composto metálico, melhor será o desempenho da imobilização da matriz. ${ }^{6}$

Deve-se tomar cuidado com o potencial de oxirredução do sistema para que se tenha o controle do estado de valência dos metais, pois a mudança de valência pode ter como consequência a formação 
de outros compostos, prejudicando a eficácia da imobilização do metal. A oxidação do cromo trivalente (octaédrico) para o estado hexavalente (tetraédrico) não aumenta somente a característica de toxidade do elemento, mas também sua solubilidade e mobilidade, dificultando a imobilização do metal na matriz de cimento. Na Figura 2 é apresentada a curva de solubilidade calculada para $\mathrm{Cr}(\mathrm{OH})_{3}$, em função do $\mathrm{pH}$.

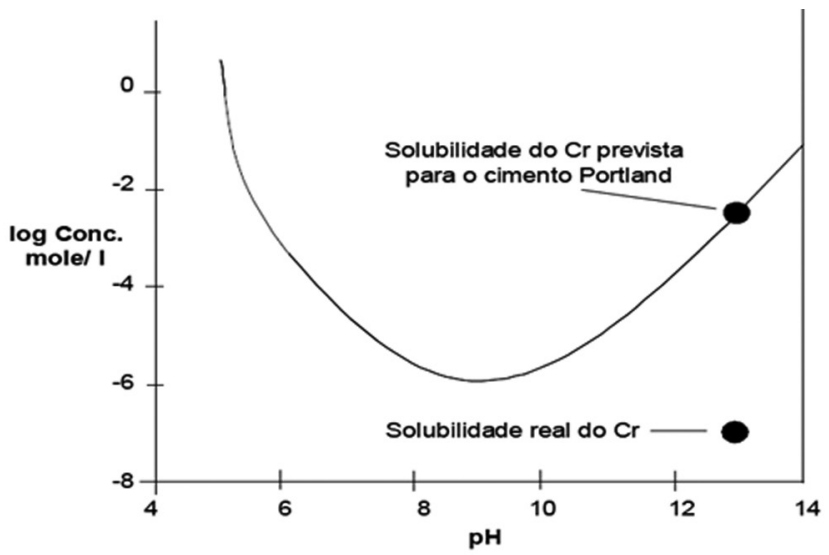

Figura 2. Curva de solubilidade calculada para $\mathrm{Cr}(\mathrm{OH})_{3}$ em função do $\mathrm{pH}$

Estudos realizados por Duchesne e Laforest, ${ }^{7}$ com o intuito de verificar o efeito da utilização de diferentes tipos de aditivos ao cimento, mostram uma significativa eficiência quanto ao aprisionamento do metal cromo. Estes autores observaram que os íons cromo são quase que totalmente imobilizados nas fases sólidas hidratadas do cimento, independentemente da razão inicial água:sólido.

Assim, na tentativa de inertizar o cromo presente no resíduo do couro (serragem cromada) em uma matriz cimentícia, foi realizado um tratamento prévio para que todo o material orgânico do resíduo se decompusesse em diferentes produtos químicos, com valores de $\mathrm{pH}$ distintos.

\section{PARTE EXPERIMENTAL}

\section{Materiais}

Utilizou-se um cimento Portland CP-II 32 Z, da marca Itaú, comercialmente encontrado na cidade de São Carlos, São Paulo. Este cimento apresentou área superficial igual a $0,93 \mathrm{~m}^{2} / \mathrm{g}$, massa unitária de $1,00 \mathrm{~kg} / \mathrm{dm}^{3}$ e massa específica igual a $3,11 \mathrm{~kg} / \mathrm{dm}^{3}$.

A serragem de couro, proveniente de peles bovinas, oriundas do processo de curtimento foi coletada manualmente e de forma aleatória diretamente das pilhas de descarte de uma indústria de luvas de raspa de couro da cidade de Bocaina, estado de São Paulo. O material foi preservado em sacos plásticos e longe da incidência de calor para preservar sua umidade original.

Este mesmo material foi utilizado anteriormente em trabalhos de Tachard, ${ }^{6}$ no qual foram observadas algumas características físicas e estruturais das raspas. A densidade aproximada é de $0,25 \mathrm{~g} / \mathrm{cm}^{3}$, a umidade (\% em massa) é de $44,5 \%$ e a perda ao fogo (\% massa) é de $94,8 \%$.

A serragem, que é obtida após o processo de curtimento, apresenta coloração azulada e, devido à sua elevada umidade (quase a metade do seu peso), é denominada de couro wet blue. A Figura 3 mostra, por meio de micrografias obtidas por microscopia eletrônica de varredura, aspectos das estruturas fibrosas que compõem as raspas.

A elevada perda ao fogo $(94,8 \%)$ é justificada pela presença de material orgânico (fibras proteicas) que volatiliza durante a calcina-
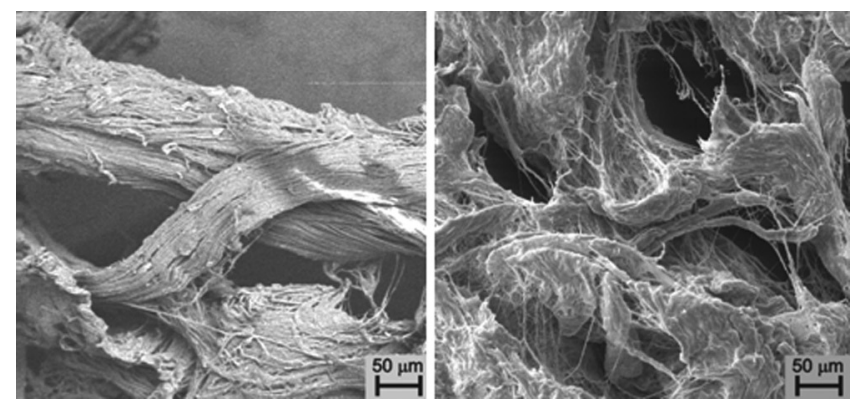

Figura 3. Micrografias obtidas por microscopia eletrônica de varredura $(\mathrm{MEV})$ da serragem de couro, em duas regiões distintas

ção, deixando uma pequena quantidade de cinzas (5,2\%). A Figura 4 mostra a principal fase cristalina detectada por DRX das cinzas resultantes do ensaio de perda ao fogo. As reflexões basais em destaque (Figura 4) são relativas ao $\mathrm{Cr}_{2} \mathrm{O}_{3}$ advindo da oxidação do íon cromo, que é o principal componente inorgânico presente neste material. Foi realizada também microanálise por EDS e os principais elementos detectados estão apresentados também na Figura 4.

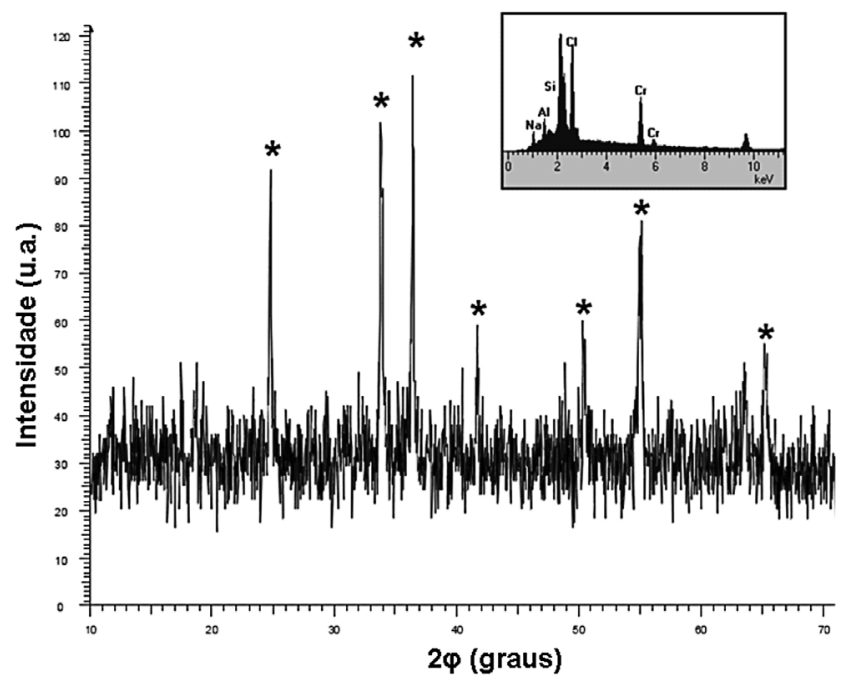

Figura 4. Difratograma de raios $X$ da cinza da serragem de couro. Os picos indicados com asteriscos são de $\mathrm{Cr}_{2} \mathrm{O}_{3}$. No detalhe, microanálise (EDS) da serragem de couro

Dentre os elementos inorgânicos detectados, observou-se a presença do cloro (43\% em peso atômico), cromo (29\%) e sódio (18\%), além de traços de alumínio e silício. Provavelmente, estes elementos foram detectados devido à grande quantidade de insumos utilizados no processo de tratamento do couro, desde sua conservação, onde ocorre o salgamento das peles, passando pelo processo de ribeira, até o curtimento, quando o cromo é utilizado.

Segundo os limites estabelecidos pela norma NBR 10.004, o cromo é o único elemento que pode conferir toxidade a este resíduo. Assim, foi quantificado com maior precisão o teor de cromo presente na serragem de couro pelo método de absorção atômica e o valor obtido foi de $30,034 \mathrm{~g} / \mathrm{kg}$ na base seca, ou seja, 3\% em massa, que é compatível com os valores reportados na literatura. ${ }^{2}$

$\mathrm{O}$ ácido utilizado neste trabalho para o pré-tratamento da serragem de couro foi o ácido fosfórico (concentração de $85 \%$ de $\mathrm{P}_{2} \mathrm{O}_{5}, \mathrm{pH}=$ 1,5 e densidade de $1,646 \mathrm{~g} / \mathrm{cm}^{3}$ ) e a base utilizada para o tratamento da serragem cromada foi a soda cáustica, $\mathrm{NaOH}$, em escamas (do fabricante Sansão) com concentração de $75 \%$, comercialmente encontrada em casas de materiais de construção. 


\section{Métodos}

\section{Pré-tratamento do resíduo}

A serragem de couro foi submetida a um pré-tratamento químico afim de que toda a cadeia proteica (matéria orgânica) fosse quebrada. Assim, quando este material previamente tratado é adicionado ao cimento, evita-se que ocorra a decomposição da matéria orgânica ao longo do tempo (envelhecimento), o que pode levar à formação de grandes vazios na matriz de cimento Portland, afetando significativamente sua resistência mecânica.

Além da diminuição da resistência mecânica, a decomposição da serragem de couro na matriz de cimento Portland pode aumentar a permeabilidade e, consequentemente, a possibilidade de lixiviação do íon cromo, se este não estiver quimicamente ligado a alguma fase insolúvel.

Em estudos recentes, Oliveira et al. ${ }^{8}$ tentaram extrair o cromo dos rejeitos de couro e, ao utilizarem hidróxido de sódio e ácido fosfórico, conseguiram a redução de aproximadamente $99,6 \%$ do cromo presente no resíduo, isto é, o teor de cromo que era de cerca de $27,150 \mathrm{mg} / \mathrm{kg}$ no couro wet blue foi reduzido para $84,7 \mathrm{mg} / \mathrm{kg}$ (colágeno). As Equações 2 e 3 ilustram o mecanismo de extração do cromo pelo tratamento ácido ou básico:

$$
\begin{aligned}
& \text { Couro- } \mathrm{Cr}+\mathrm{H}_{3} \mathrm{PO}_{4} \rightarrow \text { colágeno }+\mathrm{CrPO}_{4} \\
& \text { Couro- } \mathrm{Cr}+\mathrm{NaOH} \rightarrow \text { colágeno }+\mathrm{Cr}(\mathrm{OH})_{3}
\end{aligned}
$$

No primeiro meio, foi usada solução química com $\mathrm{pH}$ ácido para a quebra das cadeias de proteínas. As soluções foram preparadas adicionando-se a serragem de couro a um ácido fosfórico com concentração de $85 \%$ juntamente com a água em diferentes proporções ácido:água (1:2, 1:3, 1:4, 1:5, 1:6, 1:12).

A solução (água + ácido) foi preparada em um béquer, sendo o resíduo adicionado gradativamente, enquanto o sistema era aquecido a uma temperatura de aproximadamente $70-80{ }^{\circ} \mathrm{C}$. Esta mistura foi agitada até que toda a parte sólida da serragem de couro fosse dissolvida, formando assim uma solução viscosa de resíduo tratado que apresentou uma coloração esverdeada e um odor forte, característico do couro.

No segundo meio, foi usada solução química com $\mathrm{pH}$ básico para a quebra das cadeias de proteínas. As soluções foram preparadas adicionando-se a serragem de couro a uma base, com concentração de $75 \%$, juntamente com a água em diferentes proporções base:água (1:2, 1:3, 1:4, 1:5, 1:6, 1:12). Essas proporções, como o ocorrido na condição ácida, foram suficientes para dissolver toda a quantidade de resíduo sólido (serragem de couro) adicionado.

A solução de resíduo sólido tratado em meio básico apresentou uma coloração verde escuro e com odor característico de couro, mas com maior intensidade se comparado com o odor da solução de resíduo tratado em meio ácido. O tempo de preparo e a viscosidade das soluções de resíduo tratado em meio básico foram semelhantes aos observados em meio ácido.

Com as soluções de resíduo tratado em meio ácido e em meio básico, preparou-se uma terceira solução, neutra, formada pela misturada de quantidades iguais das soluções preparadas anteriormente. As soluções neutras foram preparadas somente nas proporções em que se utilizou solução ácida e básica nas proporções 1:6 e 1:12, por serem mais interessantes técnica e economicamente, já que utilizam menores quantidades de reagentes químicos.

$\mathrm{O}$ pH das soluções contendo a serragem de couro tratada quimicamente foi medido utilizando-se um pHmetro modelo Q400 BD, da Quimis, a fim de se verificar a mudança destes valores quando estas soluções são preparadas com diferentes relações de reagente:água.
Preparação e análise das pastas

Com o objetivo de verificar a influência do teor de resíduo adicionado, foi observado o comportamento de pastas de cimento Portland contendo 5 e $10 \%$ de adição, em relação à massa do cimento e comparando este comportamento ao da amostra de referência (sem resíduo). Estas adições foram feitas para cada tipo de solução ácida, básica ou neutra, previamente preparadas nas proporções citadas anteriormente.

Após determinada a quantidade de água para a obtenção de uma pasta de consistência normal, segundo a norma NBR NM 43 (Cimento Portland - Determinação da pasta de consistência normal), foram adicionadas as soluções contendo o resíduo tratado, nos teores de 5 e $10 \%$ e nas diversas proporções trabalhadas, com o intuito de se avaliar sua influência no tempo de pega, de acordo com a norma NBR NM 65 (Cimento Portland - Determinação do tempo de pega).

Foram verificadas, também, as mudanças de $\mathrm{pH}$ do sistema, uma vez que as soluções de resíduo tratado possuem $\mathrm{pHs}$ variados. A importância de se medir o pH é avaliar a sua influência nos ensaios de consistência normal e de tempo de pega.

Além disso, observou-se o efeito da presença do resíduo de couro na formação de fases das pastas de cimento após 28 dias de hidratação. Para isso, utilizou-se um difratômetro Rigaku Geirgeflex ME 210GF2, com tubo de alvo de cobre de $40 \mathrm{KV}$ e $40 \mathrm{~mA}$, e sistema de filtragem de monocromador secundário de grafite curvo. Os espectros de difração foram obtidos na faixa de $2 \theta$ de $10^{\circ}$ a $80^{\circ}$, modo contínuo a $2 \% \mathrm{~min}$. As fases presentes nas amostras foram posteriormente identificadas com o auxílio do programa computacional DIFFRAC plus-EVA, com base de dados centrada no sistema JCPDS (Joint Committe on Power Diffraction Standarts).

\section{RESULTADOS E DISCUSSÃO}

\section{Potencial hidrogeniônico (pH) das pastas}

Por terem sido utilizados diferentes meios de pré-tratamento da raspa de couro, com pHs completamente distintos, seria de fundamental importância saber a influência destas soluções no $\mathrm{pH}$ da pasta de cimento, o que poderia influenciar diretamente no tempo de pega e na formação de novas fases na matriz cimentícia.

As pastas obtidas com a adição do resíduo tratado em meios ácido, básico e neutro não apresentaram diferenças significativas com relação aos valores de $\mathrm{pH}$. Todas as pastas, independentemente das concentrações e teores de adição, apresentaram valores de $\mathrm{pH}$ superiores a 12,3. Provavelmente, isso ocorreu pelo fato da quantidade adicionada (5 e 10\% em relação à massa de cimento) não ter sido suficiente para alterar o $\mathrm{pH}$ da pasta como um todo, uma vez que o cimento é, naturalmente, um material de elevada alcalinidade, da ordem de 13,5, devido principalmente ao hidróxido de cálcio resultante da reação de hidratação.

As variações dos pHs nas pastas de cimento Portland preparadas com a adição do resíduo tratado nas diferentes condições estão representadas na Figura 5. Vale notar que, apesar das curvas serem discretas entre si devido ao eixo das ordenadas expandido, os valores de $\mathrm{pH}$ ficaram na faixa de 13,45 a 12,30 para todas as situações analisadas, sendo um fator positivo uma vez que as reações de hidratação são favorecidas em ambientes de elevada alcalinidade ( $\mathrm{pH}$ acima de $12,0),{ }^{9}$ o que é mantido para todas as situações.

\section{Tempo de pega}

As pastas de cimento Portland contendo serragem de couro tratada nos três meios (ácido, básico e neutro) apresentaram um comportamento semelhante, com um inicial aumento no tempo de 


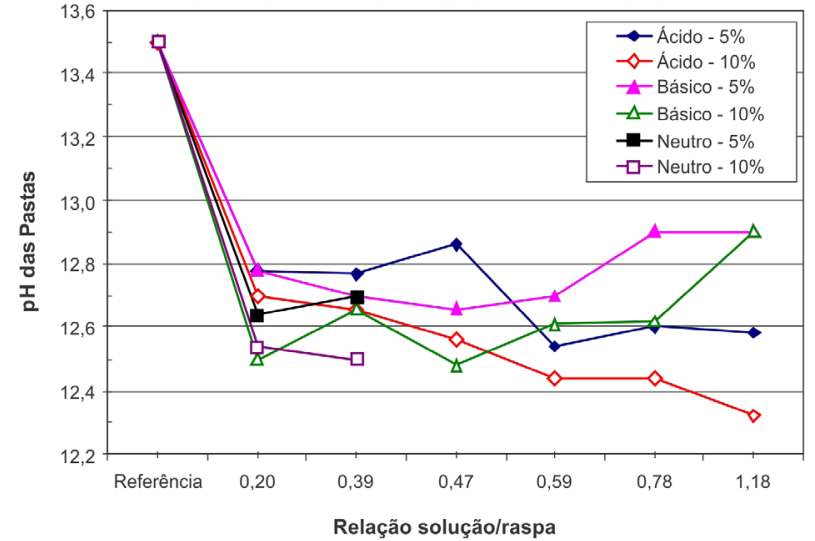

Figura 5. Variação do pH das pastas de cimento Portland contendo diferentes teores de serragem de couro (raspa) tratada em meios ácido, básico e neutro, em função das concentrações utilizadas

pega, seguido de uma brusca redução, associada às menores concentrações, até valores semelhantes aos de referência, como pode ser observado na Figura 6.

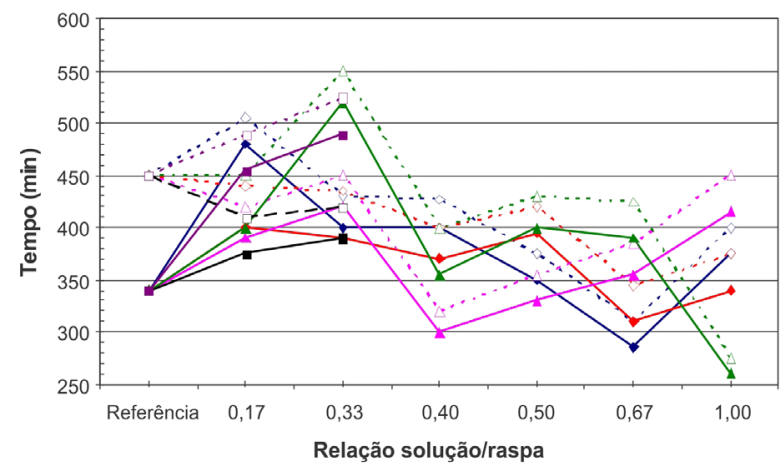

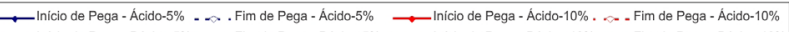

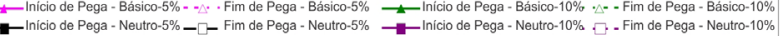

Figura 6. Tempos de início e fim de pega das pastas de cimento Portland contendo diferentes teores de serragem de couro (raspa) tratada em meios ácido, básico e neutro, em função das concentrações utilizadas

Segundo Lemos, ${ }^{10}$ a adição do hidróxido de sódio $(\mathrm{NaOH})$ e do ácido sulfúrico $\left(\mathrm{H}_{2} \mathrm{SO}_{4}\right)$ em argamassas e concretos de cimento Portland faz com que a constante hidráulica do meio decresça. Esta constante é diretamente proporcional à quantidade de poros presente na matriz de cimento e, quanto maior a quantidade de poros, maior é a facilidade da hidratação da pasta. À medida que o processo de hidratação evolui, a quantidade de vazios diminui, dificultando a hidratação e aumentando, consequentemente, o tempo de pega.

Outra explicação para este comportamento (aumento do tempo de pega do cimento em meio ácido) foi sugerida por Mehta ${ }^{11}$ para a hidratação do cimento Portland na presença de ácido fosfórico. Os sais de cálcio provenientes da reação com o ácido fosfórico são insolúveis e formam-se facilmente ao redor das partículas de cimento, durante a hidratação. Estas formações densas e insolúveis diminuem consideravelmente a hidratação pelo retardo da velocidade de ionização. Como a primeira etapa das reações dos componentes do cimento Portland com a água é por dissolução-precipitação, os componentes se ionizam, formando produtos de hidratação cristalinos.

Baseado nesses mecanismos propostos pelos autores citados anteriormente, era de se esperar que a adição de $10 \%$ da solução ácida causasse um aumento no tempo de pega superior ao tempo de pega das pastas com $5 \%$ de adição. No entanto, este fato não foi observado, mesmo em ensaios com réplica.

Para os sistemas com solução básica, além da soda cáustica provocar uma diminuição da constante hidráulica, Mehta ${ }^{11}$ também sugere que a presença de $\mathrm{NaOH}$ pode provocar o carreamento de partículas de silicatos de cálcio minerais solúveis presentes no cimento Portland, retardando a formação dos primeiros geles de hidratação.

Já nos sistemas constituídos por soluções neutras, reações paralelas, com a possibilidade de formação de sais de fosfato de sódio, modificaram os resultados observados separadamente com as adições de solução ácida e básica.

\section{Formação de fases (DRX)}

Além das fases normalmente encontradas em uma matriz de cimento Portland, como a Portlandita $\left(\mathrm{Ca}(\mathrm{OH})_{2}\right)$ e silicato de cálcio hidratado (C-S-H), foi possível observar a presença da fase etringita $\left(\mathrm{C}_{6} \mathrm{AS}_{3} \mathrm{H}_{32}\right)$, que comumente se forma no início do processo de hidratação (início da pega).

As amostras das pastas de cimento preparadas com o resíduo tratado em meio ácido apresentaram ainda a fase fosfato de cálcio, como esperado, devido à utilização do ácido fosfórico. Nesta análise (Figura 7), os picos difratados confirmam a reação do ácido fosfórico com o cálcio fornecido pelo cimento Portland.

Os picos de carbonato de cálcio podem ser provenientes da eflorescência do cálcio, pois o cimento pode ser entendido como uma ma-

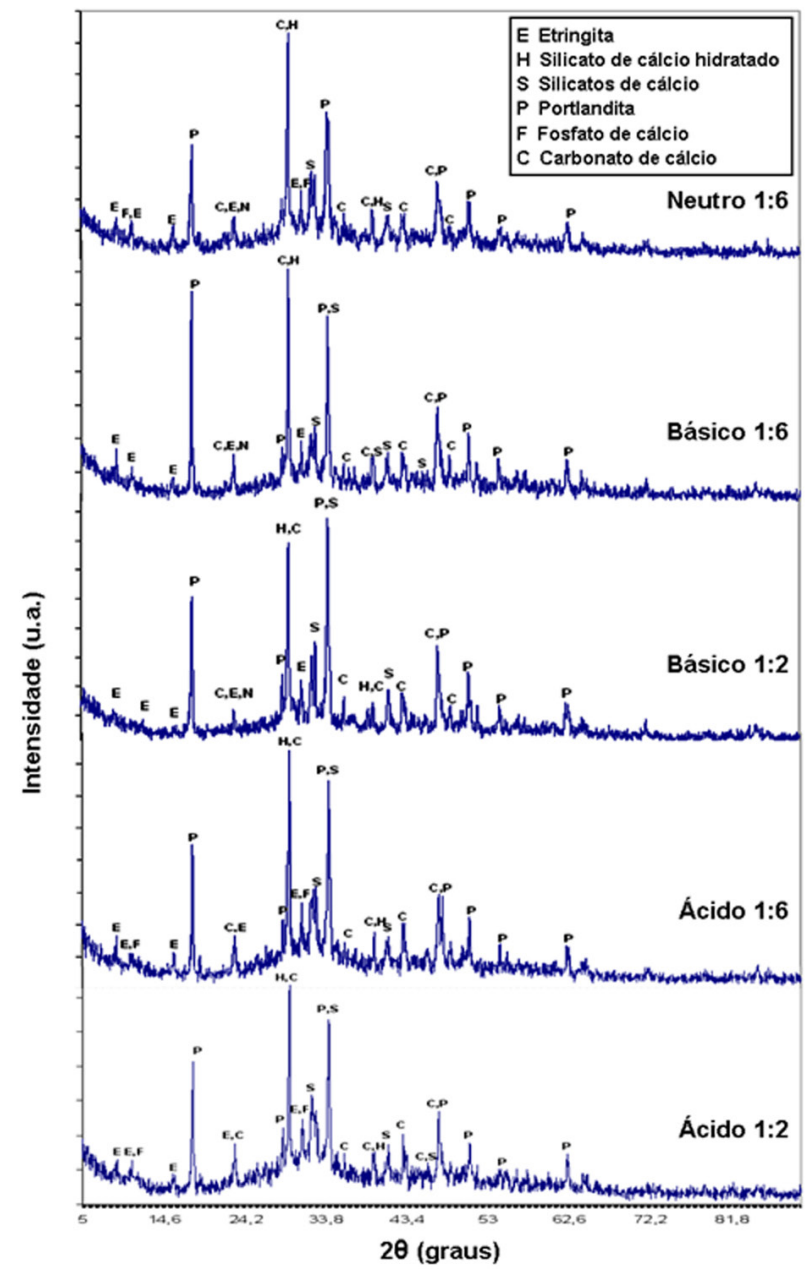

Figura 7. Difratogamas (DRX) das pastas de cimento Portland com adição de $10 \%$, em peso, de solução contendo serragem de couro (raspa) tratada em diferentes meios e concentrações 
triz sólida, intercalada por capilares que contêm uma solução aquosa de componentes de cimento solúveis em água - predominantemente hidróxido de cálcio. À medida que o cimento endurece, o hidróxido de cálcio presente nos capilares (ou poros) da superfície reage com o dióxido de carbono no ar para formar carbonato de cálcio. ${ }^{12}$ Se um filme de água condensada estiver presente na superfície do concreto, o hidróxido de cálcio pode se espalhar sobre toda a superfície e cobri-la com carbonato de cálcio insolúvel em água. Vale aqui esclarecer que as amostras apresentaram uma coloração esbranquiçada superficial, possivelmente devido à esta formação de carbonato de cálcio.

As fases comumente encontradas na hidratação do cimento, C$\mathrm{S}-\mathrm{H}$, portlandita $\left(\mathrm{Ca}(\mathrm{OH})_{2}\right)$ e a etringita, foram também encontradas nas amostras com resíduo tratado em meio básico, além da presença de picos de $\mathrm{NaOH}$, como pode ser visualizado na Figura 7. No difratograma de raios $\mathrm{X}$ obtido para a amostra contendo o resíduo tratado em meio neutro pode-se observar uma combinação entre os resultados anteriores, com a presença das fases normais de hidratação do cimento, picos de fosfato de cálcio, bem como de $\mathrm{NaOH}$.

A presença do $\mathrm{NaOH}$ pode ser uma grande preocupação para o desenvolvimento tecnológico deste material, uma vez que a reação dos álcalis (predominantemente sódio, potássio e magnésio) presentes na matriz cimentícia com a sílica dos agregados (areia ou brita) tem como consequência uma danosa expansibilidade, que pode comprometer a segurança das estruturas. ${ }^{13}$ Assim, a adição do resíduo de couro tratado em meio ácido apresenta-se mais interessante do ponto de vista tecnológico, por não afetar consideravelmente o tempo de pega e o pH das pastas, além de não formar compostos potencialmente deletérios à matriz cimentícia.

\section{CONCLUSÕES}

A partir das análises dos resultados obtidos, e considerando as condições experimentais adotadas e utilizadas para o desenvolvimento deste trabalho, pode-se concluir que o resíduo de couro (serragem ou raspa de couro) pode ser facilmente dissolvido em meio ácido $\left(\mathrm{H}_{3} \mathrm{PO}_{4}\right)$ e básico $(\mathrm{NaOH})$, de forma a resultar em uma solução aquosa homogênea.

Os tempos de pega das pastas contendo soluções de resíduo tratado nos três meios (ácido, básico e neutro) foram inicialmente superiores aos da amostra de referência, seguidos de uma brusca redução, associada às menores concentrações, com exceção, das soluções básicas de alta concentração de sódio.

A adição de resíduo tratado em diferentes pHs minimiza a formação de Portlandita e favorece a formação de compostos (fases secundárias), tais como os fosfatos de cálcio, em meios ácidos (adição de ácido fosfórico) ou $\mathrm{NaOH}$, em meios básicos (adição de $\mathrm{NaOH}$ ).

A adição do resíduo de couro tratado em meio ácido apresentase mais interessante do ponto de vista tecnológico, por não afetar consideravelmente o tempo de pega e o $\mathrm{pH}$ das pastas, além de não formar compostos potencialmente deletérios à matriz cimentícia.

A incorporação de soluções contendo serragem de couro em matrizes de cimento Portland requer ainda mais estudos, de caráter interdisciplinar, sobretudo das áreas de Engenharia de Materiais, Química e Ambiental.

\section{AGRADECIMENTOS}

Ao CNPq — Conselho Nacional de Desenvolvimento Científico e Tecnológico; PPGCEM-UFSCar — Programa de Pós-graduação em Ciência e Engenharia de Materiais da Universidade Federal de São Carlos.

\section{REFERÊNCIAS}

1. http://www.brazilianleather.com.br, acessada em Julho 2010.

2. Pacheco, J. W. F.; Curtumes. Série P+L, CETESB: São Paulo, 2009.

3. Dallago, R. M.; Smaniotto, A.; Oliveira, L. C. A.; Quim. Nova 2005, 28, 433.

4. Fujikawa, E. S.; Dissertação de Mestrado, Universidade Estadual Paulista, Brasil, 2002.

5. Glasser, F. P.; J. Hazard. Mater. 1997, 52, 151.

6. Tachard, A. L. R. S.; Dissertação de Mestrado, Universidade Federal de São Carlos, Brasil, 2006.

7. Duchesne, J.; Laforest, G.; Cem. Concr. Res. 2004, 34, 1173.

8. Oliveira, D. Q. L.; Carvalho, K. T. G.; Bastos, A. R. R.; Oliveira, L. C. A.; Marques, J. J. G.; Nascimento, R. S. M.; Rev. Bras. Ciênc. Solo 2008, 32, 417.

9. Gordon, J. N.; Pinnock, W. R.; Moore, M. M.; Cem. Concr. Comp. 1996, 18,371 .

10. Lemos, R. G.; Tese de Doutorado, Universidade Federal do Rio Grande do Sul, Brasil, 2006.

11. Mehta, P. K.; Monteiro, P. J. M.; Concreto: estrutura, propriedades e materiais, Pini: São Paulo, 1994.

12. Yuan, S. Y.; Dissertação de Mestrado, Universidade Federal de São Carlos, Brasil, 2009.

13. Reis, M. O. B.; Silva, A. M. S.; Reacções álcalis-sílica: recomendações gerais para prevenir a deterioração do betão, LNEC: Lisboa (Boletim Técnico. ITCM 23), 1997. 